\title{
Social-ecological considerations for the sleep health of rural mothers
}

\author{
Alexandra R. Fischer ${ }^{1} \cdot$ Sha-Rhonda M. Green ${ }^{2}$. \\ Heather E. Gunn ${ }^{1} \mathbb{D}$
}

Received: 11 July 2020 / Accepted: 30 September 2020 / Published online: 20 October 2020

(C) Springer Science+Business Media, LLC, part of Springer Nature 2020

\begin{abstract}
Using a social-ecological framework, we identify social determinants that interact to influence sleep health, identify gaps in the literature, and make recommendations for targeting sleep health in rural mothers. Rural mothers experience unique challenges and protective factors in maintaining adequate sleep health during the postpartum and early maternal years. Geographic isolation, barriers to comprehensive behavioral medicine services, and intra-rural ethno-racial disparities are discussed at the societal (e.g., public policy), social (e.g., community) and individual levels (e.g., stress) of the social-ecological model. Research on sleep health would benefit from attention to methodological considerations of factors affecting rural mothers such as including parity in population-level analyses or applying community-based participatory research principles. Future sleep health programs would benefit from using existing social support networks to disseminate sleep health information, integrating behavioral health services into clinical care frameworks, and tailoring culturally-appropriate Telehealth/mHealth programs to enhance the sleep health of rural mothers.
\end{abstract}

Keywords Rural · Sleep health · Women's health · Social-ecological model $\cdot$ Ethno-racial disparities

Heather E. Gunn

hegunn@ua.edu

1 Department of Psychology, University of Alabama, Box 87034, Tuscaloosa, AL 35487, USA

2 School of Social Work, University of Alabama, Tuscaloosa, USA

\section{Introduction}

Sleep health is a critical element of women's health across the lifespan (Jackson et al. 2020). Sleep health comprises parameters such as duration, continuity, and timing, which are strongly linked to health and well-being (Buysse 2014). Although epidemiological studies indicate little variance between women and men in obtaining sufficient sleep (Grandner 2019), women generally experience greater risk for insomnia (Petrov et al. 2014) and report greater sleep disturbances and worse sleep quality than men (Wang et al. 2018), particularly during life transitional phases with reproductive hormonal change (Meers et al. 2019). Anticipated physiological and psychosocial changes associated with the perinatal period (before and after childbirth) challenge the maintenance of sleep health across pregnancy, immediate postpartum, and the early years of motherhood (Christian et al. 2019). Moreover, poor maternal sleep health can contribute to concomitant downstream negative health consequences such as postpartum depression (PPD; Bhati and Richards 2015; Carroll et al. 2019; Okun et al. 2018), chronic pelvic pain disorders (Cheng and Li 2008; Cosar et al. 2014) and cardiovascular disease risk (Troxel et al. 2010). Thus, motherhood brings about many changes to sleep health, which in turn contributes to other downstream negative consequences.

Whereas many women have temporary changes to sleep health while adjusting to motherhood, the intersection of geography, income, education, and race can drastically amplify changes to, and impact from, poor sleep health. In particular, poor health outcomes during the postpartum period are likely compounded in rural women due to the prevalence of financial strain in rural areas, lack of coordinated postnatal care, geographic isolation from medical services and mental health stigma (Hung et al. 2017; 
Kozhimannil et al. 2017; Levin and Hanson 2020; Mollard et al. 2016; Nidey et al. 2020). Moreover, within rural populations, socio-demographic differences and disparities contribute to elevated risk for poor sleep health and other related health outcomes (Doering et al. 2017; Mersky et al., 2020). Individuals located at the margins of mainstream rural communities (e.g., migrant farm workers), with intersectional identities composed of multiple social positions embedded within systems of inequality (López and Gadsden 2016), may experience even more barriers to accessing healthcare (Ceballos et al. 2013; Schminkey et al. 2019), are currently underrepresented in research efforts (Hargraves 2002; Jackson et al. 2020; Schminkey et al. 2019), and are underserved in their communities (Henning-Smith et al. 2017; Tangel et al. 2019).

A focus on a modifiable health behavior (sleep) in a vulnerable population (rural mothers) is critical and pressing, especially in light of the current economic and healthcare crises due to Covid-19, which may disproportionally affect women (Thapa et al. 2020) and contributes to increased distress during the perinatal period (Berthelot et al. 2020). Importantly, dimensions of sleep health are modifiable and can be targeted across overlapping socialecological domains to improve overall health outcomes in rural areas for clinical and general populations (Chang et al. 2012; Douthit et al. 2015; Grandner et al. 2012). Although literature on structural and social determinants of sleep health specifically in rural populations is limited, we draw evidence from other bodies of literature, such as studies of rural PPD in which sleep is featured as a prominent symptom (Lawson et al. 2015; Tham et al. 2016) and is partially accounted for by social determinants (Nidey et al. 2020).

Thus, using a social-ecological framework, the current review will highlight existing research focused on the sleep health in rural mothers, identify gaps in the literature, and make recommendations for targeting sleep health in this population. In particular, we outline the social determinants that interact to influence the sleep health of rural mothers with a focus on socioeconomic and ethno-racial health disparities. We apply a social-ecological framework (Fig. 1; Grandner 2019) to organize existing literature, and proposed mechanisms by which rural mothers are at a greater risk for poor sleep health, and in turn may be more likely to have negative consequences because of this risk. Use of an ecological model can provide clarity about how social determinants impact sleep health beyond an individual focus to include social/interpersonal (e.g., culture) and societal (e.g., public policy) domains that shape health outcomes (Grandner 2017; López and Gadsden 2016). Societal, social, and individual-level categories are not entirely discrete; broad societal-level factors influence social and individual contributions to sleep health and vice-versa. However, we organize the current literature around these themes to facilitate identification of gaps in the literature and next steps for this population.
Fig. 1 Social-ecological model of sleep. From Social-ecological model of sleep health in M.A. Grandner (Ed.), Sleep and Health (p. 49), by M.A. Grandner, Academic Press, 2019. Copyright 2019 by Elsevier Inc

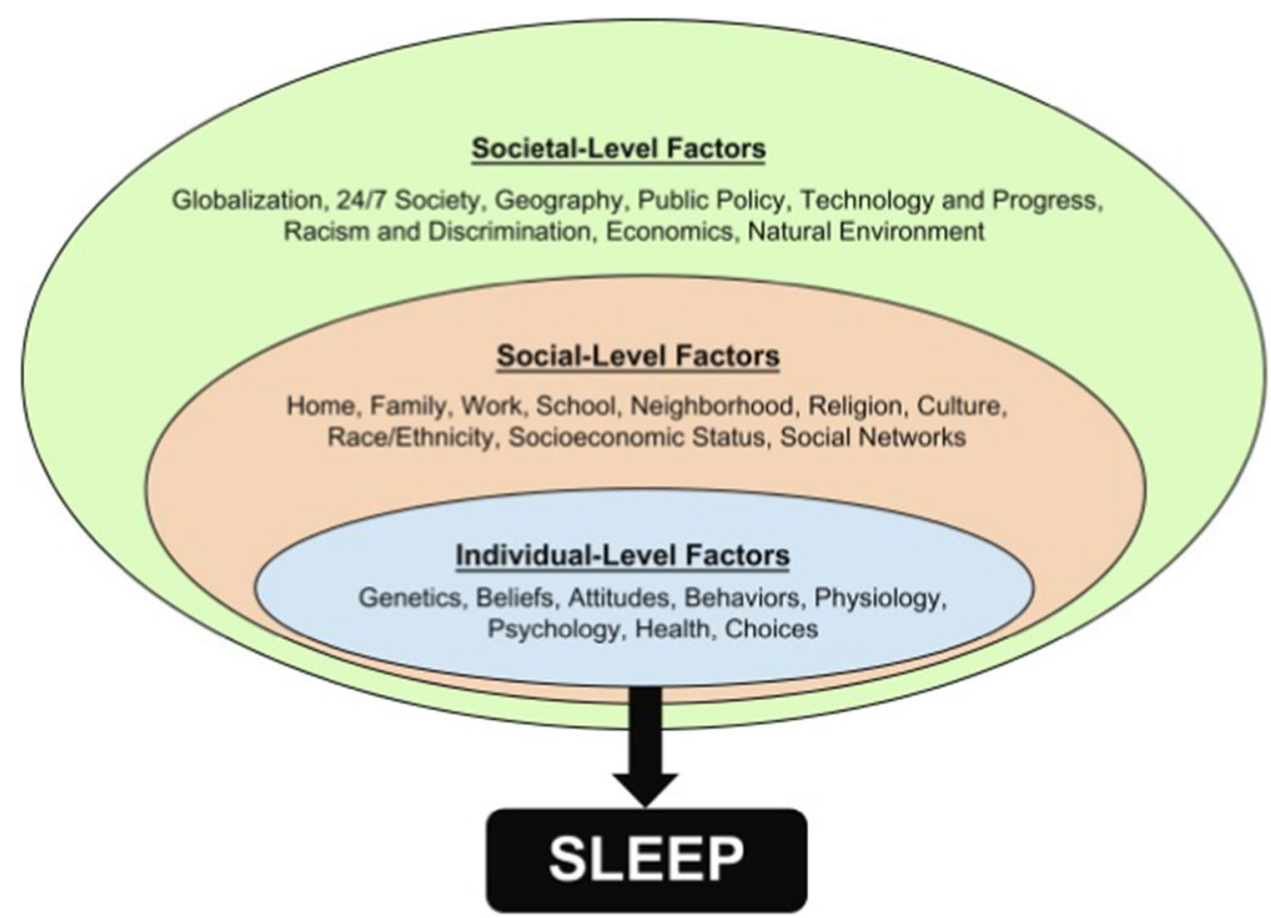




\section{Societal-level factors}

Societal influences include aspects of larger systems that contribute to sleep health in groups or individuals. Some factors are amenable to large scale change (e.g., public policy to reduce sleepy driving); however, studying sleep health likely requires contextual considerations of other immutable factors. To that end, approximately 60 million individuals $(20 \%$ of the US population) reside in rural America (Ratcliffe et al. 2016). The geographic isolation of rural communities creates unique challenges for women who need to access comprehensive and coordinated perinatal care, including behavioral medicine services (Han et al. 2015). Rural mothers often live far from their health care providers and subsequently travel long distances for obstetric or specialized perinatal care- a potential source of psychosocial distress and increased risk for childbirth-related complications (DiPietro Mager et al. 2020; Hung et al. 2016). The average distance of travel for rural intrapartum care (i.e. labor and delivery) is 29 miles and access to hospitals with obstetric units with specialized medical staff continues to decline in rural areas at a rate of 9\% from 2004 to 2014 (Hung et al. 2017). Consequently, family physicians are increasingly relied upon to provide comprehensive postpartum care. (Hung et al. 2016). This is particularly concerning for the sleep health of rural mothers because family practitioners may have fewer resources (e.g., training, staff) to coordinate behavioral sleep health services for postpartum women (Henning-Smith et al. 2017; Kozhimannil et al. 2018). Furthermore, women in rural areas report fewer regular sources of specialized women's healthcare (DiPietro Mager et al. 2020) and only 25\% of rural family clinics are geographically co-located with behavioral health services, as compared to urban areas in which $40 \%$ of services are co-located (Levin and Hanson 2020).

Shifts in national and state healthcare policies may contribute to rural healthcare access disparities. In states that did not expand Medicaid coverage under the Patient Protection and Affordable Care Act (2010), low-income women, disproportionally Black and rural, reported worse health indicators, less perceived access to medical care, and less preventative care utilization than low-income women in Medicaid- expanded coverage states (Han et al. 2015). Indeed, there is a significant gap in coverage for low-income mothers in non-Medicaid expansion states because temporary perinatal healthcare coverage may end as soon as 8 weeks postpartum for those who would otherwise not qualify for Medicare with income exceeding $18 \%$ of the federal poverty limit (Adams and Johnston 2016). Systematic limitations to healthcare access challenge the recommendations of practitioners who overwhelmingly call for more comprehensive postpartum care (American College of Obstetrics and Gynecology [ACOG] 2018), including consideration of behavioral indicators of health such as sleep (Hamilton et al.
2018; Sharkey 2013). Expanded healthcare access for new mothers through national and state policy change is associated with improved health indicators, particularly for underserved populations (Dickson et al. 2018; Han et al. 2015); thus, they should be considered for intervention to improve the sleep health of rural mothers.

One important aspect of policy change that could enhance sleep health in mothers who reside in non-Medicaid expansion states is guaranteeing paid maternity leave. Postpartum sleep is associated with highly fragmented sleep in the first 12 weeks postpartum (Montgomery-Downs et al. 2010), short sleep duration (Doering et al. 2017), and excessive daytime sleepiness (Filtness et al. 2014) yet mothers often report returning to work within 8 weeks of giving birth. Recently, paid postpartum leave demonstrated positive effects on mental and physical health in Australia, particularly for those who had insecure work situations (Hewitt et al. 2017). While some workers in the US are eligible for 12 weeks of unpaid maternity leave under the Family and Medical Leave Act, the US is the only developed nation to not provide nationally protected paid maternity/parental leave (Jou et al. 2018).

Racial and ethnic minority residents, who account for 6-20\% of rural residents by region, (Rastogi et al., 2010), may be more vulnerable to poor health and socio-economic disparities that exacerbate poor sleep health in mothers (Caldwell et al. 2016; Grandner et al. 2016; Jones et al. 2020; Kumar Chattu et al. 2019; Petrov and Lichstein 2016; Weaver et al. 2015) Ethno-racial diversity has historically existed in rural communities and it continues to increase with demand for labor in agricultural, natural resources, and construction industries (Lee \& Sharp 2017; Lobao 2014). Yet media imagery and research efforts disproportionately focus on White rural residents (Kozhimannil and HenningSmith 2018). Inclusion in an ethno-racial rural minority, such as in the Black Belt of the Southeastern US, may also confer unique strengths and coping strategies that positively affect well-being such as the physical environment, ties to kinship, and spirituality (Ceballos et al. 2013; Dolbier et al. 2013; Kozhimannil and Henning-Smith 2018; Mollard et al. 2016). Thus, understanding the complex social context of health disparities for ethno-racial minorities is crucial to addressing the dynamics of intra-rural health disparities, particularly for rural Indigenous people, descendants of enslaved people, and recent immigrants affected by the historical context of systematic oppression and contemporary structural inequity (Caldwell et al. 2016; Hargraves 2002; Kozhimannil and Henning-Smith 2018).

In sum, at the societal level, the geographic isolation of rural communities and lack of access to healthcare disproportionally affects rural women. Future research and healthcare policy initiatives would benefit from examining the societal factors that influence sleep health (i.e., assessing 
rurality) in mothers. Expanding our understanding of intrarural ethno-racial disparities that inform the complex relationship between societal determinants and sleep health would also be beneficial.

\section{Social-level factors}

The community, culture, and interpersonal relationships that shape rural women's lives (e.g., family, socioeconomic position) influence rural maternal sleep health. Rurality, strongly associated with low socioeconomic-position, is a strong determinant of sleep health in the general population and partially accounts for some of the sleep health disparities among ethno-racial groups and along the rural-urban continuum (Grandner et al. 2016). For example, sleep health beyond the first 6 weeks postpartum is more likely to remain poor for mothers of low socioeconomic position and is associated with increased anxiety and depression (Sivertsen et al. 2015; Tomfohr et al. 2015).

The social climate of rural communities may place mothers at a disadvantage in experiencing role strain, a state of increased stress due to competing demands of multiple social roles that is associated with poor mental and physical health outcomes, particularly with PPD (Evans et al. 2016; Mollard et al. 2016). Traditional gender roles and conservative family values are more prominent in rural areas, yet there are fewer jobs that can support single-income families in traditionally male-dominated fields (Lobao 2014); there are also fewer jobs with employment benefits such as paid parental leave (Lichter 2012). Therefore, rural mothers commonly return to work sooner than urban counterparts (Weaver et al. 2015) and may need to reconcile a desire to stay at home with the financial necessity of returning to work sooner. For ethnoracial minorities, balancing multiple roles in the context of gender and racism can further compound the balancing of role responsibilities which, in turn, exacerbates role strain (Green-Davis 2016; Schminkey et al. 2019).

Role strain and socioeconomic-related stressors can be mitigated by the social support network. Indeed, social support is related to better sleep and psychological health among mothers of diverse socio-demographic backgrounds (Belete and Misgan 2019; Mersky et al. 2020; Sinai and Tikotzky 2012). In rural families, close-knit communities, familial women, and parental partners comprise the core support systems (Gjesfjeld et al. 2012; Reynolds and Walther 2020). Literature on social support and sleep health in rural mothers was scarce; however, strong family ties, more intergenerational co-caregiving, and flexibility in parental responsibilities are associated with less risk for PPD in rural mothers (Brown and Lumley 2000; Edwards et al. 2012).

Social support enhances sleep health, particularly in already vulnerable populations (Mersky et al. 2020), and rural mothers prefer informal, non-medical advice during the transition to parenthood (Mollard et al. 2016, 2017); therefore, existing social networks for rural mothers may be considered a resource in disseminating information about sleep health and promoting early intervention. Given the risk of false health information about maternal and infant sleep spreading through social networks (Craswell et al. 2018; Rouhi et al. 2019), collaboration between health professionals and communities could focus on accurate dissemination. This could include training in sleep health promotion and assessment for perinatal in-home visitation care models, peer-to-peer counseling, and structured social networks for new mothers with culturally-relevant consultation with sleep health educators (Krans and Davis 2014).

Increasingly, mothers are turning to virtual social networking platforms for emotional and instrumental support (Craswell et al. 2018) which could be another avenue of support for mothers facing geographic isolation. In an effort to combat the lack of behavioral health resources in rural areas, technology has facilitated the possibility of behavioral health specialists reaching rural communities through Telehealth services (Parsons et al. 2017). Tailored sleep health programs in rural areas through Telehealth interventions are promising, but many rural communities do not have affordable, high-quality broadband internet access, which prevents synchronous Telehealth interventions from reaching underserved rural areas (Drake et al. 2019). On the other hand, mobile health (mHealth, which only requires cellular service) programs could be used to help mothers manage sleep health during the transition to motherhood, as suggested by emerging research in preventative programs targeting PPD symptoms (Dol et al. 2020; Drake et al. 2014).

Most mothers experience changes in sleep quality and quantity during the transition to parenthood, but for some mothers, it can become a more severe problem that is overlooked in clinical postpartum care (ACOG 2018; Sharkey 2013). Severe sleep disruption is an almost universal complaint for the estimated $10-15 \%$ of women who develop severe psychological disorders after childbirth (e.g., depression, psychosis; Lawson et al. 2015; Wilkerson and Uhde 2018); therefore, the lack of assessment and treatment of sleep problems, and related mental health disorders, in rural communities is critical (Dolbier et al. 2013; Mollard et al. 2016; Weaver et al. 2015). Although the literature comparing rural versus urban rates of mental health disorders is mixed, it is likely that rural mothers face unique challenges in healthcare access, which can make the burden of mental health disorders more severe. Again, the geographic isolation of rural communities translates to declining rates of health care providers in rural areas with specialized training (Hamilton et al. 2018; Henning-Smith et al. 2017; Hung et al. 2017) in the unique challenges of maternal sleep (e.g., nocturnal infant care) and the risk of comorbid severe 
psychopathology. Furthermore, the widespread reliance on pharmacologic treatments for behavioral health problems in rural areas (Carpenter-Song and Snell-Rood 2017; Metse and Bowman, 2020) is problematic in terms of sleep health; behavioral interventions (e.g., CBTi) are considered bestpractice for chronic sleep problems (Kalmbach et al. 2019; Van Straten et al. 2017). Moreover, pregnant and nursing mothers often prefer non-pharmacologic treatment due to concerns about the potential teratogenic effects on the health of their children (Ceulemans et al. 2019).

For rural ethno-racial minority populations, access to quality healthcare in rural communities may be worse due to discrimination in interactions with health care institutions (Hardeman et al. 2016), particularly for Black women (Hoffman et al. 2016; Smith et al. 2020), Hispanic/Latinx women (Schminkey et al. 2019), and American Indian women (Serbin 2016). There is also emerging evidence that sexual and gender minority mothers, who are more vulnerable to poor sleep health (Cunningham et al. 2018), may also experience discrimination and barriers to healthcare access in rural communities (Barefoot et al. 2015; Puckett et al. 2011).

Mothers in rural communities face geographic isolation, less access to high-quality internet, and barriers to health care in the community, even so, there is strength in closeknit relationships with peers and care providers which can enhance cost-efficient preventative sleep health interventions. For example, maternal sleep health programs could be folded into existing care models such as community-based perinatal care models that use home-visitation, paraprofessional/peer counseling (e.g., doulas, peer health educators), and comprehensive birthing centers (e.g., midwife-led model of care) to improve mother and infant health outcomes while simultaneously reducing cost of care for low-income families (Alliman et al. 2019; Dodge et al. 2014).

\section{Individual-level factors}

The societal and social determinants of sleep health described above converge to influence rural mothers' sleep health at the individual level. While it is important to address individual factors, they may be the result of, or influenced by, broader determinants, and should be considered embedded within the social-ecological system (Grandner 2019). This is particularly important as the field increasingly recognizes that poor maternal sleep and stress are related to- but not unilaterally defined by-infant and toddler sleep patterns (Sharkey et al. 2016; Zambrano et al. 2016).

Poor sleep health is a hallmark of perinatal anxiety and depression and it is almost universally present among severe mood disorders and/or postpartum psychosis (Bhati and Richards 2015; Lawson et al. 2015; Okun et al. 2018). PPD is the most common post-childbirth complication, occurring in approximately $10-15 \%$ of US childbearing women (Bauman et al. 2020; Bhati and Richards 2015; Chang et al. 2012; Hasin and Grant 2015; Nidey et al. 2020); it is associated with numerous negative physical and psychological health outcomes in mothers and infants (Slomian et al. 2019). Although the literature regarding differences between rural and urban prevalence of sleep and anxiety/depression is mixed, the social context of rural life (e.g., geographic isolation, social stigma) translates to a greater impact on the lives of rural women and their families (Chang et al. 2012). Research would benefit from a deeper understanding of anxiety in rural mothers; indeed, anxiety in mothers may be more pervasive than depression at the sub-clinical level (Field 2018) and may be exacerbated by the stressors of rural life. Because of the elevated risk of depression and anxiety associated with poor sleep health, the promotion of sleep health in rural communities could serve as an acceptable and efficacious intervention for better health outcomes overall.

Rural women may also face barriers in establishing positive health behaviors that are linked to sleep health and that are protective factors against the development of postpartum depression, postpartum weight gain (Herring et al. 2019), and negative health outcomes, such as cardiovascular disease risk and diabetes (Guardino et al. 2018). These individual health behaviors are all affected by more broad community and societal determinants; for example, mothers in rural areas, especially low-income and ethno-racial minority women, are more likely to have inadequate physical activity compared to urban women. Regular exercise is associated with better sleep quality, yet rural women are less active due to challenges in the built environment (e.g., no sidewalks, fewer exercise facilities) of rural communities (Bagley et al. 2018; King et al. 2000).

The individual factors that shape maternal sleep are influenced by upstream determinants such as socio-economic position and physical environments. As our understanding of the complexity of maternal sleep health continues to grow, the range of interventions to improve sleep health in mothers should include the social context beyond individual characteristics and health behaviors.

\section{Gaps in the literature and recommendations for future research}

Current literature suggests that sleep health is likely worse, or at least a pressing concern, for rural mothers. Sleep health is becoming increasingly relevant in the mood, anxiety, and health challenges that mothers encounter. Access to providers and systems, role strain, and cultural values (e.g., independence and mental health stigma) suggest that mothers residing in rural areas may have sleep health issues that are more likely to go undetected and treated. Furthermore, for 
individuals with pre-existing sleep problems or for those who develop sleep problems during pregnancy or after childbirth, there is less access to behavioral sleep medicine resources in rural communities. However, based on the current literature, it is difficult to determine the extent of sleep health problems in this population. Moreover, it is not yet known how some aspects of rurality could mitigate poor sleep health.

An emerging literature suggests that better sleep health is associated with interpersonal support (Gunn et al. 2014; Kent de Grey et al. 2018, 2015; Troxel et al. 2007). In partnered high-income mothers, tangible paternal involvement (e.g., nighttime infant caregiving) is associated with better sleep health (Tikotzky et al. 2015) and at least one finding in a population of low-income mothers suggests social support is associated with better sleep health (Mersky et al. 2020). In addition, belonging to a church community, which is more common in rural areas, is associated with lower odds of PPD (Cheadle and Dunkel Schetter 2018; Jesse and Swanson 2007). However, we know little of the impact of the types of close relationships that are more common in lowincome rural populations (Barnett et al. 2012) that could be protective of sleep health in new mothers (Carroll et al. 2019). Cohabitating multigenerational co-caregivers (i.e., grandparents) and extended kinship networks (Blalock et al. 2004; Brown et al. 2000) offer tangible social support such as childcare and co-parenting which could offset sleep problems in new mothers. For example, a live-in family member may help a new mother sleep at night by providing nighttime care for the infant. On the other hand, new mothers without these social networks could fare worse due to isolation and loneliness (Kurina et al. 2011).

As outlined below, the literature would benefit from a combination of community-based participatory research efforts to explore the particular sleep health needs of this population, as well as population-based studies of rural residents with expanded analysis of sociodemographic differences (e.g., gender, parity, and race/ethnicity). First, it is important to determine the extent of sleep health issues in rural mothers and identify targets for improving. When advancing towards improving sleep health, we recommend drawing from models in related fields; in particular, a stepped approach to sleep health promotion and integrated behavioral healthcare (Krug and Umylny 2016; Rybarczyk and Mack, 2011).

\section{Methodological considerations}

The field would benefit from these methodological considerations in identifying the population, drawing out the context, and community-based participatory research. Researchers and practitioners would benefit from identifying the rurality of their patients and research participants' community.
Indeed, clinicians and researchers in urban hospitals and primary care clinics may be already working with rural mothers who bypass local healthcare or do not have providers in their community (Radcliff et al. 2003; Sanders et al. 2015). Socioeconomic position and ethno-racial diversity are rarely accounted for in sleep research (Grandner et al. 2016), and even less so in perinatal sleep and women's health research (Jackson et al. 2020; Nidey et al. 2020). Population-level studies of regional health disparities would benefit from accounting for gender differences and reporting parity (number of children) for women of childbearing age (Evans et al. 2016; Metse and Bowman 2020; Young et al. 2020). In clinical practice, patients could self-identify as rural in their medical records so that clinicians consider this aspect of their care. For example, it may cue practitioners to be sensitive to cultural values and norms in low-income, rural women (e.g., independence, positive thinking) that can impede engagement in psychological treatment (SnellRood et al. 2017). Geographically, awareness of the rurality of a patient could invite more flexible modes of treatment delivery (e.g., Telehealth services) and coordination with supportive services within their local community. Future research would also benefit from drawing out the context of rural sleep health through community-based participatory methodology (Israel et al. 2010), including qualitative interviews with mothers and practitioners (Carpenter-Song and Snell-Rood 2017) in partnership with local community organizations.

\section{Potential strategies for improving sleep health}

Using a stepped approach to care, promotion of rural perinatal sleep health can draw support from existing programs tailored for socioeconomically-disadvantaged, ethno-racially diverse women (Drake, et al. 2014; Pekmezi et al. 2013; Stevens et al. 2018). In particular, trauma informed, intersectional care with collaboration in the community has demonstrated positive gains in health outcomes (Sweeney et al. 2018). At the societal level, sleep health researchers and clinicians may advocate for public policy changes to expand healthcare coverage for rural mothers. At the social level, sleep health professionals may use existing social support networks to provide accurate information about sleep hygiene, stress management, and infant sleep schedule strategies to promote sleep health for the whole family. In order to expand the availability of behavioral sleep medicine treatment in rural communities, primary care practitioners would benefit from collaboration with remote sleep health professionals through Telehealth consultation (Parsons et al. 2017); however, care should not be limited to telehealth. Other available interventions may bridge the gap between specialists and community care providers to improve behavioral health care in rural mothers. 
To that end, to improve sleep health in rural populations, it is useful to draw upon existing, brief and flexible models of behavioral sleep treatments. Brief Behavioral Treatment for Insomnia (BBTI) is one such paradigm. It is a manualized treatment to reduce symptoms of insomnia through behavioral modification (Buysse et al. 2011) administrable by non-psychologist/psychiatrist health professionals in 2-4 sessions with flexible delivery methods (e.g., in-person and remote sessions, or solely via video-conferencing; Gunn et al. 2019). BBTI is suited for rural populations because it requires few office visits (if in-person) and focuses on physiological and behavioral aspects of insomnia which may be more acceptable to those who are distrustful of psychological interventions (Buysse et al. 2011). Furthermore, sleep disturbance may be one of the few modifiable risk factors of PPD (Bhati and Richards 2015). Therefore, BBTI, or a similar behavioral model, could be a cost-effective and acceptable way to reduce incidence of postpartum depression (Swanson et al. 2011). While BBTI has not been applied to rural perinatal populations, it has been tested in other clinical populations (e.g., older adults, veterans) with overlapping treatment barriers (Gunn et al. 2019).

Integrating behavioral health services into rural primary care can also be achieved through increased screening for behavioral health problems (Drake et al. 2014) and provider-led discussions of mental health during perinatal appointments (Bauman et al. 2020). Additionally, focusing on strengthening social support (Mersky et al. 2020) and fostering strong alliances between patients and their health care providers can help improve mental health outcomes for mothers and their families (Batra 2019). For example, peer support has been helpful in improving adherence to treatment for obstructive sleep apnea (Parthasarathy et al. 2013) and a systematic review by Ramchand et al. (2017) found that didactic peer support has led to behavioral changes that positively affect general health outcomes. New mothers often seek advice from friends and family before consulting with a health professional (Rouhi et al. 2019), therefore, peer-topeer parenting groups could be designed as a cost-effective community-focused program. As previously discussed in the context of social-level influences on sleep health, existing perinatal care models that use peer counseling and strong patient-provider alliances could integrate a focus on sleep health in rural mothers. Although such models of care are not necessarily designed for rural populations, collaborative relationships with a focus on social determinants of health may be the best antidote to rising healthcare costs and closure of rural hospitals (Parsons et al. 2019).

Sleep health is a modifiable behavior that can influence outcomes in mothers, including postpartum depression and heightened psychosocial stress during the transition to motherhood. Research, clinical practice, and program development regarding the sleep health of mothers in the perinatal period would benefit from examining the upstream socialecological determinants, which includes consideration of geographic location (i.e., rurality). Considerations for rural mothers, in particular, will advance research among underserved populations and serve as an example of the importance of examining sleep health beyond the individual, while emphasizing the diverse, intersectional nature of social determinants of sleep health.

Funding This work was supported by the Pickens County Pilot Project Grant 2019-2020, College of Community Health Sciences, University of Alabama.

\section{Compliance with ethical standards}

Conflict of interest Alexandra R. Fischer has no known conflict of interest to disclose. Sha-Rhonda M. Green has no known conflict of interest to disclose. Heather E. Gunn havs no known conflict of interest to disclose.

Human and Animal Rights and Informed Consent This article does not contain any studies with human participants or animals performed by any of the authors.

\section{References}

Adams, K. E., \& Johnston, E. M. (2016). Insuring women in the United States before, during, and after pregnancies. American Journal of Public Health, 106, 585-586. https://doi.org/10.2105/ AJPH.2016.303132

Alliman, J., Stapleton, S. R., Wright, J., Bauer, K., Slider, K., \& Jolles, D. (2019). Strong start in birth centers: Socio-demographic characteristics, care processes, and outcomes for mothers and newborns. Birth, 46, 234-243. https://doi.org/10.1111/birt.12433

American College of Obstetricians and Gynecologists. (2018). Optimizing postpartum care. Committee Opinion, Number 736, 131.

Bagley, E. J., Fuller-Rowell, T. E., Saini, E. K., Philbrook, L. E., \& El-Sheikh, M. (2018). Neighborhood economic deprivation and social fragmentation: Associations with children's sleep. Behavioral Sleep Medicine, 16, 542-552. https://doi. org/10.1080/15402002.2016.1253011

Barefoot, K. N., Smalley, K. B., \& Warren, J. C. (2015). Psychological distress and perceived barriers to care for rural lesbians. Journal of Gay and Lesbian Mental Health, 19, 347-369. https://doi. org/10.1080/19359705.2015.1041629

Barnett, M. A., Mills-Koonce, W. R., Gustafsson, H., \& Cox, M. (2012). Mother-grandmother conflict, negative parenting, and young children's social development in multigenerational families. Family Relations, 61, 864-877. https://doi.org/10.111 1/j.1741-3729.2012.00731.x

Batra, P. (2019). Integrated mind/body care in women's health: a focus on well-being, mental health, and relationships. Obstetrics and Gynecology Clinics of North America, 46, 469-483. https://doi. org/10.1016/j.ogc.2019.04.006

Bauman, B. L., Ko, J. Y., Cox, S., D’Angelo, MPH, D. V., Warner, L., Folger, S., Tevendale, H. D., Coy, K. C., Harrison, L., Barfield, W. D. (2020) Postpartum depressive symptoms and provider discussions about perinatal depression-United States, 2018. 
MMWR Morbidity and Mortality Weekly Report, 69, 575-581 https://doi.org/10.15585/mmwr.mm6919a2

Belete, H., \& Misgan, E. (2019). Determinants of insomnia among mothers during postpartum period in northwest Ethiopia. Sleep Disorders. https://doi.org/10.1155/2019/3157637

Berthelot, N., Lemieux, R., Garon-Bissonnette, J., Drouin-Maziade, C., Martel, É., \& Maziade, M. (2020). Uptrend in distress and psychiatric symptomatology in pregnant women during the COVID19 pandemic. Acta Obstetricia et Gynecologica Scandinavica, 99, 848-855. https://doi.org/10.1111/aogs.13925

Bhati, S., \& Richards, K. (2015). A systematic review of the relationship between postpartum sleep disturbance and postpartum depression. Journal of Obstetric, Gynecologic, and Neonatal Nursing, 44, 350-357. https://doi.org/10.1111/1552-6909.12562

Blalock, L. L., Tiller, V. R., \& Monroe, P. A. (2004). "They get you out of courage:" Persistent deep poverty among former welfarereliant women. Family Relations, 53, 127-137. https://doi.org/1 0.1111/j.0022-2445.2004.00003.x

Brown, S., \& Lumley, J. (2000). Physical health problems after childbirth and maternal depression at six to seven months postpartum. BJOG An International Journal of Obstetrics and Gynaecology, 107, 1194-1201. https://doi.org/10.1111/j.1471-0528.2000.tb116 07.x

Buysse, D. J. (2014). Sleep health: Can we define it? Does it matter? Sleep, 37, 9-17. https://doi.org/10.5665/sleep.3298

Caldwell, J. T., Ford, C. L., Wallace, S. P., Wang, M. C., \& Takahashi, L. M. (2016). Intersection of living in a rural versus urban area and race/ethnicity in explaining access to health care in the United States. American Journal of Public Health, 106, $1463-$ 1469. https://doi.org/10.2105/AJPH.2016.303212

Carpenter-Song, E., \& Snell-Rood, C. (2017). The changing context of rural america: A call to examine the impact of social change on mental health and mental health care. Psychiatric Services, 68, 5. https://doi.org/10.1176/appi.ps.201600024

Carroll, J. E., Teti, D. M., Hall, M. H., \& Christian, L. M. (2019). Maternal sleep in pregnancy and postpartum part ii: Biomechanisms and intervention strategies. Current Psychiatry Reports, 21, 3. https://doi.org/10.1007/s11920-019-1000-9

Ceballos, M., Wallace, G., \& Goodwin, G. (2013). Postpartum depression among african-american and latina mothers living in small cities, towns, and rural communities. J Am Acad Nurse Pract, 9, 726-760. https://doi.org/10.1007/s40615-016-0295-Z

Ceulemans, M., Lupattelli, A., Nordeng, H., Odalovic, M., Twigg, M., \& Foulon, V. (2019). Women's beliefs about medicines and adherence to pharmacotherapy in pregnancy: Opportunities for community pharmacists. Current Pharmaceutical Design, 25, 469-482. https://doi.org/10.2174/1381612825666190321110420

Chang, J. J., Salas, J., Habicht, K., Pien, G. W., Stamatakis, K. A., \& Brownson, R. C. (2012). The association of sleep duration and depressive symptoms in rural communities of missouri, tennessee, and arkansas. Journal of Rural Health, 28, 268-276. https ://doi.org/10.1111/j.1748-0361.2011.00398.x

Cheadle, A. C. D., \& Dunkel Schetter, C. (2018). Mastery, self-esteem, and optimism mediate the link between religiousness and spirituality and postpartum depression. Journal of Behavioral Medicine, 41, 711-721. https://doi.org/10.1007/s10865-018-9941-8

Cheng, C. Y., \& Li, Q. (2008). Integrative review of research on general health status and prevalence of common physical health conditions of women after childbirth. Women's Health Issues, 18, 267-280. https://doi.org/10.1016/j.whi.2008.02.004

Christian, L. M., Carroll, J. E., Teti, D. M., \& Hall, M. H. (2019). Maternal sleep in pregnancy and postpartum part i: mental, physical, and interpersonal consequences. Current Psychiatry Reports, 21. Current Medicine Group LLC 1. https://doi. org/https://doi.org/10.1007/s11920-019-0999-y
Cosar, E., Güngör, A. Ç., Gencer, M., Uysal, A., Hacivelioğlu, S. O., Özkan, A., \& Şen, H. M. (2014). Sleep disturbance among women with chronic pelvic pain. International Journal of Gynecology and Obstetrics, 126, 232-234. https://doi.org/10.1016/j. ijgo.2014.03.034

Craswell, A., Jones, C. M., Gleeson, D. M., \& Jones, C. M. (2018). Women's use of social networking sites related to childbearing: An integrative review. Women and Birth, 32, 294-302. https:// doi.org/10.1016/j.wombi.2018.10.010

Cunningham, T. J., Xu, F., Town, M. (2018). Prevalence of five health-related behaviors for chronic disease prevention among sexual and gender minority adults-25 U S States and Guam, 2016. Morbidity and Mortality Weekly Report, 67, 888-893 https://doi.org/10.15585/mmwr.mm6732a4

Dickson, M. F., Staton, M., Tillson, M., Leukefeld, C., Webster, J. M., \& Oser, C. B. (2018). The affordable care act and changes in insurance coverage and source of health care among highrisk rural, substance-using, female offenders transitioning to the community. Journal of Health Care for the Poor and Underserved, 29, 843-863. https://doi.org/10.1353/ hpu.2018.0064

DiPietro Mager, N. A., Zollinger, T. W., Turman, J. E., Zhang, J., \& Dixon, B. E. (2020). Routine healthcare utilization among reproductive-age women residing in a rural maternity care desert. Journal of Community Health. https://doi.org/10.1007/s1090 0-020-00852-6

Dodge, K. A., Goodman, W. B., Murphy, R. A., O’Donnell, K., Sato, J., \& Guptill, S. (2014). Implementation and randomized controlled trial evaluation of universal postnatal nurse home visiting. American Journal of Public Health, 104, 1. https://doi.org/10.2105/ AJPH.2013.301361

Doering, J. J., Szabo, A., Goyal, D., \& Babler, E. (2017). Sleep quality and quantity in low-income postpartum women. MCN The American Journal of Maternal/Child Nursing, 42, 166-172. https ://doi.org/10.1097/NMC.0000000000000323

Dol, J., Richardson, B., Murphy, G. T., Aston, M., McMillan, D., \& Campbell-Yeo, M. (2020) Impact of mobile health interventions during the perinatal period on maternal psychosocial outcomes. JBI Database of Systematic Reviews and Implementation Reports, 18, 30-55. https://doi.org/10.11124/JBISR IR-D-19-00191

Dolbier, C. L., Rush, T. E., Sahadeo, L. S., Shaffer, M. L., \& Thorp, J. (2013). Relationships of race and socioeconomic status to postpartum depressive symptoms in rural African American and nonhispanic white women. Maternal and Child Health Journal, 17, 1277-1287. https://doi.org/10.1007/s10995-012-1123-7

Douthit, N., Kiv, S., Dwolatzky, T., \& Biswas, S. (2015). Exposing some important barriers to health care access in the rural USA. Public Health, 129, 611-620. https://doi.org/10.1016/j. puhe.2015.04.001

Drake, C., Zhang, Y., Chaiyachati, K. H., \& Polsky, D. (2019). The limitations of poor broadband internet access for telemedicine use in rural america: An observational study. Annals of Internal Medicine, 171, 382-384. https://doi.org/10.7326/M19-0283

Drake, E., Howard, E., \& Kinsey, E. (2014). Online screening and referral for postpartum depression: An exploratory study. Community Mental Health Journal, 50, 305-311. https://doi. org/10.1007/s10597-012-9573-3

Edwards, R. C., Thullen, M. J., Isarowong, N., Shiu, C.-S., Henson, L., \& Hans, S. L. (2012). Supportive relationships and the trajectory of depressive symptoms among young, African American mothers. Journal of Family Psychology, 26, 585-594. https://doi. org/10.1037/a0029053

Evans, K. L., Millsteed, J., Richmond, J. E., Falkmer, M., Falkmer, T., \& Girdler, S. J. (2016). Working sandwich generation 
women utilize strategies within and between roles to achieve role balance. PLOS ONE, 11, 6. https://doi.org/10.1371/journ al.pone. 0157469

Field, T. (2018). Postnatal anxiety prevalence, predictors and effects on development: A narrative review. Infant Behavior and Development, 51, 24-32. https://doi.org/10.1016/j.infbeh.2018.02.005

Filtness, A. J., MacKenzie, J., \& Armstrong, K. (2014). Longitudinal change in sleep and daytime sleepiness in postpartum women. PLoS ONE, 9, 7. https://doi.org/10.1371/journal.pone.0103513

Gjesfjeld, C. D., Weaver, A., \& Schommer, K. (2012). Rural women's transitions to motherhood: Understanding social support in a rural community. Journal of Family Social Work, 15, 435-448. https://doi.org/10.1080/10522158.2012.719182

Grandner, M. A., Jackson, N. J., Pak, V. M., \& Gehrman, P. R. (2012). Sleep disturbance is associated with cardiovascular and metabolic disorders. Journal of Sleep Research, 21, 427-433. https:// doi.org/10.1111/j.1365-2869.2011.00990.x

Grandner, M. A. (2017). Sleep, health, and society. Sleep Medicine Clinics, 12, 1-22. https://doi.org/10.1016/j.jsmc.2016.10.012

Grandner, M. A. (2019). Social-ecological model of sleep health. In M. A. Grander (Ed.), Sleep and Health (pp. 45-53). Elsevier. https ://doi.org/10.1016/B978-0-12-815373-4.00005-8

Grandner, M. A., Williams, N. J., Knutson, K. L., Roberts, D., \& Jean-Louis, G. (2016). Sleep disparity, race/ethnicity, and socioeconomic position. Sleep Medicine, 18, 7-18. https://doi. org/10.1016/j.sleep.2015.01.020

Green-Davis, S.-R. (2016) Multiple Roles as Predictors of Subjective Well-Being in African American Women. Doctoral Dissertation, Walden University.

Guardino, C. M., Hobel, C. J., Shalowitz, M. U., Ramey, S. L., \& Dunkel Schetter, C. (2018). Psychosocial and demographic predictors of postpartum physical activity. Journal of Behavioral Medicine, 41, 668-679. https://doi.org/10.1007/s10865-018-9931-x

Gunn, H. E., Troxel, W. M., Hall, M. H., \& Buysse, D. J. (2014). Interpersonal distress is associated with sleep and arousal in insomnia and good sleepers. Journal of Psychosomatic Research, 76, 242-248. https://doi.org/10.1016/j.jpsychores.2013.11.010

Gunn, H. E., Tutek, J., \& Buysse, D. J. (2019). Brief behavioral treatment of insomnia. Sleep Medicine Clinics, 14(2), 235-243. https ://doi.org/10.1016/j.jsmc.2019.02.003

Hamilton, N., Stevens, N., Lillis, T., \& Adams, N. (2018). The fourth trimester: Toward improved postpartum health and healthcare of mothers and their families in the United States. Journal of Behavioral Medicine, 41, 571-576. https://doi.org/10.1007/ s10865-018-9969-9

Han, X., Nguyen, B. T., Drope, J., \& Jemal, A. (2015). Health-related outcomes among the poor: Medicaid expansion vs. non-expansion states. PLoS ONE, 10, 12. https://doi.org/10.1371/journ al.pone. 0144429

Hardeman, R. R., Medina, E. M., \& Kozhimannil, K. B. (2016). Structural racism and supporting black lives - the role of health professionals. New England Journal of Medicine, 375, 2113-2115. https://doi.org/10.1056/NEJMp1609535

Hargraves, M. (2002). Elevating the voices of rural minority women. American Journal of Public Health, 92, 514-515. https://doi. org/10.2105/AJPH.92.4.514

Hasin, D. S., \& Grant, B. F. (2015). The national epidemiologic survey on alcohol and related conditions (NESARC) waves 1 and 2: Review and summary of findings. Social Psychiatry and Psychiatric Epidemiology, 50, 1609-1640. https://doi.org/10.1007/ s00127-015-1088-0

Henning-Smith, C., Almanza, J., \& Kozhimannil, K. B. (2017). The maternity care nurse workforce in rural U S hospitals. JOGNNJournal of Obstetric, Gynecologic, and Neonatal Nursing, 46, 411-422. https://doi.org/10.1016/j.jogn.2017.01.010
Herring, S. J., Yu, D., Spaeth, A., Pien, G., Darden, N., Riis, V., et al. (2019). Influence of sleep duration on postpartum weight change in black and hispanic women. Obesity, 27, 295-303. https://doi. org/10.1002/oby.22364

Hewitt, B., Strazdins, L., \& Martin, B. (2017). The benefits of paid maternity leave for mothers' post-partum health and wellbeing: Evidence from an Australian evaluation. Social Science and Medicine, 182, 97-105. https://doi.org/10.1016/j.socsc imed.2017.04.022

Hoffman, K. M., Trawalter, S., Axt, J. R., \& Oliver, M. N. (2016). Racial bias in pain assessment and treatment recommendations, and false beliefs about biological differences between blacks and whites. Proceedings of the National Academy of Sciences of the United States of America, 113, 4296-4301. https://doi. org/10.1073/pnas.1516047113

Hung, P., Henning-Smith, C. E., Casey, M. M., \& Kozhimannil, K. B. (2017). Access to obstetric services in rural counties still declining, with 9 percent losing services, 2004-14. Health Affairs, 36, 1663-1671. https://doi.org/10.1377/hlthaff.2017.0338

Hung, P., Kozhimannil, K. B., Casey, M. M., \& Moscovice, I. S. (2016). Why are obstetric units in rural hospitals closing their doors? Health Services Research, 51, 1546-1560. https://doi. org/10.1111/1475-6773.12441

Israel, B. A., Coombe, C. M., Cheezum, R. R., Schulz, A. J., Mcgranaghan, R. J., Lichtenstein, R., et al. (2010). Community-based participatory research: A Capacity-building approach for policy advocacy aimed at eliminating health disparities. Public Health, 100, 2094-2102.

Jackson, C. L., Powell-Wiley, T. M., Gaston, S. A., Andrews, M. R., Tamura, K., \& Ramos, A. (2020). Racial/ethnic disparities in sleep health and potential interventions among women in the United States. Journal of Women's Health, 29, 435-442. https:// doi.org/10.1089/jwh.2020.8329

Jesse, D. E., \& Swanson, M. S. (2007). Risks and resources associated with antepartum risk for depression among rural southern women. Nursing Research, 56, 378-386. https://doi. org/10.1097/01.NNR.0000299856.98170.19

Jones, R. D., Jackson, W. B., Mazzei, A., Chang, A. M., Buxton, O. M., \& Jackson, C. L. (2020). Ethnoracial sleep disparities among college students living in dormitories in the United States: A nationally representative study. Sleep Health, 6, 40-47. https:// doi.org/10.1016/j.sleh.2019.10.005

Jou, J., Kozhimannil, K. B., Abraham, J. M., Blewett, L. A., \& McGovern, P. M. (2018). Paid maternity leave in the united states: associations with maternal and infant health. Maternal and Child Health Journal, 22, 216-225. https://doi.org/10.1007/s1099 5-017-2393-x

Kalmbach, D., Cheng, P., Arnedt, J. T., Anderson, J. R., Roth, T., Fellman-Couture, C., et al. (2019). Treating insomnia improves depression, maladaptive thinking, and hyperarousal in postmenopausal women: Comparing cognitive-behavioral therapy for insomnia (CBTI), sleep restriction therapy, and sleep hygiene education. Sleep Medicine, 55, 124-134.

Kent de Grey, R. G., Uchino, B. N., Trettevik, R., Cronan, S., \& Hogan, J. N. (2018). Social support and sleep: A meta-analysis. Health Psychology, 37, 787-798. https://doi.org/10.1037/hea0000628

Kent de Grey, R. G., Uchino, B. N., Cribbet, M. R., Bowen, K., \& Smith, T. W. (2015). Social relationships and sleep quality. Annals of Behavioral Medicine, 49, 912-917. https://doi. org/10.1007/s12160-015-9711-6

King, A. C., Castro, C., Wilcox, S., Eyler, A. A., Sallis, J. F., \& Brownson, R. C. (2000). Personal and environmental factors associated with physical inactivity among different racial-ethnic groups of US middle-aged and older-aged women. Health Psychology, 19, 354-364. https://doi.org/10.1037/0278-6133.19.4.354 
Kozhimannil, K. B., Hardeman, R. R., \& Henning-Smith, C. (2017). Maternity care access, quality, and outcomes: A systems-level perspective on research, clinical, and policy needs. Seminars in Perinatology, 41, 367-374. https://doi.org/10.1053/j.sempe ri.2017.07.005

Kozhimannil, K. B., \& Henning-Smith, C. (2018). Racism and health in rural America. Journal of Health Care for the Poor and Underserved, 29, 35-43. https://doi.org/10.1353/hpu.2018.0004

Kozhimannil, K. B., Hung, P., Henning-Smith, C., Casey, M. M., \& Prasad, S. (2018). Association between loss of hospital-based obstetric services and birth outcomes in rural counties in the United States. JAMA - Journal of the American Medical Association, 319, 1239-1247. https://doi.org/10.1001/jama.2018.1830

Krans, E. E., \& Davis, M. M. (2014). Strong start for mothers and newborns: Implications for prenatal care delivery. Current Opinion in Obstetrics and Gynecology, 26, 511-515. https:// doi.org/10.1097/GCO.0000000000000118

Krug, L., \& Umylny, P. (2016). Stories from the exam room: Case examples of healthy steps interventions at Montefiore. Integrated Early Childhood Behavioral Health in Primary Care, 191-205. https://doi.org/10.1007/978-3-319-31815-8_12

Kumar Chattu, V., Kumary, S., Manzar, D., Kumary Chattu, S., Warren Spence, D., Dilshad Manzar, M., et al. (2019). Do disparities in sleep duration among racial and ethnic minorities contribute to differences in disease prevalence? Journal of Racial and Ethnic Health Disparities, 6, 1053-1061. https:// doi.org/10.1007/s40615-019-00607-7

Kurina, L. M., Knutson, K. L., Hawkley, L. C., Cacioppo, J. T., Lauderdale, D. S., \& Ober, C. (2011). Loneliness is associated with sleep fragmentation in a communal society. Sleep, 34 , 1519-1526. https://doi.org/10.5665/sleep. 1390

Lawson, A., Murphy, K. E., Sloan, E., Uleryk, E., \& Dalfen, A. (2015). The relationship between sleep and postpartum mental disorders: A systematic review. Journal of Affective Disorders, 176, 65-77. https://doi.org/10.1016/j.jad.2015.01.017

Lee, B. A., \& Sharp, G. (2017). Ethnoracial diversity across the rural-urban continuum. The annals of the American Academy of Political and Social Science, 672, 26-45. https://doi. org/10.1177/0002716217708560

Levin, B. L., Hanson, A. (2020) Rural Behavioral Health Services. In:Foundations of Behavioral Health (pp. 301-319). Springer International Publishing, Cham https://doi.org/10.1007/9783-030-18435-3_14

Lichter, D. T. (2012). Immigration and the new racial diversity in rural America. Rural Sociology, 77, 3-35. https://doi.org/10.1 111/j.1549-0831.2012.00070.x

Lobao, L. (2014). Economic change, structural forces, and rural america: Shifting fortunes across communities. In C. Bailey, L. Jensen, \& E. Ransom (Eds.), Rural America in a Globalizing World: Problems and Prospects for the 2010s (pp. 687-702). West Virginia University Press.

López, N., Gadsden, V. (2016) Health inequities, social determinants, and intersectionality health disparities, inequity, and social determinants. Perspectives: Expert Voices in Health \& Health Care, National Academy of Medicine.

Meers, J., Stout-Aguilar, J., Nowakowski, S. (2019). Sex differences in sleep health. In: M. A. Grandner (Ed.), Sleep and Health (pp. 21-29). Elsevier. https://doi.org/https://doi.org/10.1016/ B978-0-12-815373-4.00003-4

Mersky, J. P., Lee, C. T. P., Gilbert, R. M., \& Goyal, D. (2020). Prevalence and correlates of maternal and infant sleep problems in a low-income US sample. Maternal and Child Health Journal, 24, 196-203. https://doi.org/10.1007/s10995-019-02852-y

Metse, A. P., \& Bowman, J. A. (2020). Prevalence of self-reported suboptimal sleep in Australia and receipt of sleep care: Results from the 2017 national social survey. Sleep Health, 6, 100-109. https://doi.org/10.1016/j.sleh.2019.08.010

Mollard, E., Hudson, D. B., Ford, A., \& Pullen, C. (2016). An integrative review of postpartum depression in rural U S communities. Archives of Psychiatric Nursing, 30, 418-424. https://doi. org/10.1016/j.apnu.2015.12.003

Mollard E, Hudson D B, Wilhelm S, Springer P R, Pullen C (2017) Rural women's explanatory models of postpartum depressive symptomatology. Online Journal of Rural Nursing and Health Care, 171 138-167 https://doi.org/10.14574/ojrnhc.v17i1.437

Montgomery-Downs, H. E., Insana, S. P., Clegg-Kraynok, M. M., \& Mancini, L. M. (2010). Normative longitudinal maternal sleep: The first 4 postpartum months. American Journal of Obstetrics and Gynecology, 203, 465.e1-465.e7. https://doi.org/10.1016/j. ajog.2010.06.057

Nidey, N., Tabb, K. M., Carter, K. D., Bao, W., Strathearn, L., Rohlman, D. S., et al. (2020). Rurality and risk of perinatal depression among women in the united states. The Journal of Rural Health, 36, 9-16. https://doi.org/10.1111/jrh.12401

Okun, M. L., Mancuso, R. A., Hobel, C. J., Dunkel Schetter, C., \& Coussons-Read, M. (2018). Poor sleep quality increases symptoms of depression and anxiety in postpartum women. Journal of Behavioral Medicine, 41, 703-710. https://doi.org/10.1007/ s10865-018-9950-7

Parsons, E. C., Mattox, E. A., Beste, L. A., Au, D. H., Young, B. A., Chang, M. F., \& Palen, B. N. (2017). Development of a sleep telementorship program for rural department of veterans affairs primary care providers: Sleep veterans affairs extension for community healthcare outcomes. Annals of the American Thoracic Society, 14, 267-274. https://doi.org/10.1513/AnnalsATS.20160 5-361BC

Parsons, R. J., Stacey, R. F., \& Bigelow, M. L. (2019). A guide for rural health care Collaboration and Coordination. U.S: Department of Health and Human Services.

Parthasarathy, S., Wendel, C., Haynes, P. L., Atwood, C., \& Kuna, S. (2013). A pilot study of CPAP adherence promotion by peer buddies with sleep apnea. Journal of Clinical Sleep Medicine, 09, 543-550. https://doi.org/10.5664/jcsm.2744

Patient Protection and Affordable Care Act, H.R.3590, (2010). https:// www.congress.gov/bill/111th-congress/house-bill/3590

Pekmezi, D., Marcus, B., Meneses, K., Baskin, M. L., Ard, J. D., Martin, M. Y., et al. (2013). Developing an intervention to address physical activity barriers for african-american women in the deep South (USA). Women's Health, 9, 301-312. https://doi. org/10.2217/WHE.13.20

Petrov, M. E., \& Lichstein, K. L. (2016). Differences in sleep between black and white adults: An update and future directions. Sleep Medicine, 18, 74-81. https://doi.org/10.1016/j.sleep 2015.01.011

Petrov, M. E., Lichstein, K. L., \& Baldwin, C. M. (2014). Prevalence of sleep disorders by sex and ethnicity among older adolescents and emerging adults: Relations to daytime functioning, working memory and mental health. Journal of Adolescence, 37, 587597. https://doi.org/10.1016/j.adolescence.2014.04.007

Puckett, J. A., Horne, S. G., Levitt, H. M., \& Reeves, T. (2011). Out in the country: Rural sexual minority mothers. Journal of Lesbian Studies, 15, 176-186. https://doi.org/10.1080/10894 160.2011.521101

Radcliff, T. A., Brasure, M., Moscovice, I. S., \& Stensland, J. T. (2003). Understanding rural hospital bypass behavior. The Journal of Rural Health, 19, 252-259. https://doi. org/10.1111/j.1748-0361.2003.tb00571.x

Ramchand, R., Ahluwalia, S. C., Xenakis, L., Apaydin, E., Raaen, L., \& Grimm, G. (2017). A systematic review of peer-supported interventions for health promotion and disease prevention. 
Preventive Medicine, 101, 156-170. https://doi.org/10.1016/j. ypmed.2017.06.008

Ratcliffe, M., Burd, C., Holder, K., Fields, A. (2016). Defining Rural at the U.S. Censusu Bureau. https://www2.census.gov

Reynolds, J., \& Walther, C. S. (2020). The social capital of rural demography of marriage, cohabitation, and divorce. In International Handbook on the Demography of Marriage and the Family (pp. 139-156). Springer International Publishing. https://doi. org/10.1007/978-3-030-35079-6_10

Rouhi, M., Stirling, C., Ayton, J., \& Crisp, E. P. (2019). Women's helpseeking behaviours within the first twelve months after childbirth: A systematic qualitative meta-aggregation review. Midwifery, 72, 39-49. https://doi.org/10.1016/j.midw.2019.02.005

Rybarczyk, B., \& Mack, L. (2011). Behavioral treatment of insomnia: a proposal for a stepped-care approach to promote public health. Nature and Science of Sleep, 3, 87. https://doi.org/10.2147/nss. s12975

Sanders, S. R., Erickson, L. D., Call, V. R. A., McKnight, M. L., \& Hedges, D. W. (2015). Rural health care bypass behavior: how community and spatial characteristics affect primary health care selection. The Journal of Rural Health, 31, 146-156. https://doi. org/10.1111/jrh.12093

Schminkey, D. L., Liu, X., Annan, S., \& Sawin, E. M. (2019). Contributors to health inequities in rural latinas of childbearing age: An integrative review using an ecological framework. SAGE Open, 9, 1. https://doi.org/10.1177/2158244018823077

Serbin, J. W. (2016). The impact of racism and midwifery's lack of racial diversity: A literature review. Journal of Midwifery and Women's Health, 61, 694-706. https://doi.org/10.1111/ jmwh. 12572

Sharkey, K. M. (2013). Time to treat problematic sleep disturbance in perinatal women. Behavioral Sleep Medicine, 11, 308-310. https ://doi.org/10.1080/15402002.2013.823789

Sharkey, K. M., Iko, I. N., Machan, J. T., Thompson-Westra, J., \& Pearlstein, T. B. (2016). Infant sleep and feeding patterns are associated with maternal sleep, stress, and depressed mood in women with a history of major depressive disorder (MDD). Archives of Women's Mental Health, 19, 209-218. https://doi. org/10.1007/s00737-015-0557-5

Sinai, D., \& Tikotzky, L. (2012). Infant sleep, parental sleep and parenting stress in families of mothers on maternity leave and in families of working mothers. Infant Behavior and Development, 35, 179-186. https://doi.org/10.1016/j.infbeh.2012.01.006

Sivertsen, B., Hysing, M., Dørheim, S. K., \& Eberhard-Gran, M. (2015). Trajectories of maternal sleep problems before and after childbirth: A longitudinal population-based study. BMC Pregnancy and Childbirth, 15, 1. https://doi.org/10.1186/s1288 4-015-0577-1

Slomian, J., Honvo, G., Emonts, P., Reginster, J. Y., \& Bruyère, O. (2019). Consequences of maternal postpartum depression: A systematic review of maternal and infant outcomes. Women's Health, 15, 1-55. https://doi.org/10.1177/1745506519844044

Smith, E., Sundstrom, B., \& Delay, C. (2020). Listening to women: Understanding and challenging systems of power to achieve reproductive justice in South Carolina. Journal of Social Issues, 76, 363-390. https://doi.org/10.1111/josi.12378

Snell-Rood, C., Hauenstein, E., Leukefeld, C., Feltner, F., Marcum, A., \& Schoenberg, N. (2017). Mental health treatment seeking patterns and preferences of appalachian women with depression. American Journal of Orthopsychiatry, 87, 233-241. https://doi. org/10.1037/ort0000193

Stevens, N. R., Heath, N. M., Lillis, T. A., Mcminn, K., Tirone, V., \& Mervat, S. (2018). Examining the effectiveness of a coordinated perinatal mental health care model using an intersectional-feminist perspective. Journal of Behavioral Medicine, 41, 627-640. https://doi.org/10.1007/s10865-018-9973-0
Swanson, L. M., Pickett, S. M., Flynn, H., \& Armitage, R. (2011). Relationships among depression, anxiety, and insomnia symptoms in perinatal women seeking mental health treatment. Journal of Women's Health, 20, 553-558. https://doi.org/10.1089/ jwh.2010.2371

Sweeney, A., Filson, B., Kennedy, A., Collinson, L., \& Gillard, S. (2018). A paradigm shift: Relationships in trauma-informed mental health services. BJPsych Advances, 24, 319-333. https ://doi.org/10.1192/bja.2018.29

Tangel, V., White, R. S., Nachamie, A. S., \& Pick, J. S. (2019). Racial and ethnic disparities in maternal outcomes and the disadvantage of peripartum black women: A multistate analysis, 2007-2014. American Journal of Perinatology, 36, 835-848. https://doi. org/10.1055/s-0038-1675207

Tham, E. K. H., Tan, J., Chong, Y. S., Kwek, K., Saw, S. M., Teoh, O. H., et al. (2016). Associations between poor subjective prenatal sleep quality and postnatal depression and anxiety symptoms. Journal of Affective Disorders, 202, 91-94. https://doi. org/10.1016/j.jad.2016.05.028

Thapa, S. B., Mainali, A., Schwank, S. E., \& Acharya, G. (2020). Maternal mental health in the time of the COVID-19 pandemic. Acta Obstetricia et Gynecologica Scandinavica, 99, 7. https:// doi.org/10.1111/aogs.13894

Tikotzky, L., Sadeh, A., Volkovich, E., Manber, R., Meiri, G., \& Shahar, G. (2015). Infant sleep development from 3 to 6 months postpartum: Links with maternal sleep and paternal involvement. Monographs of the Society for Research in Child Development, 80, 107-124. https://doi.org/10.1111/mono.12147

Tomfohr, L. M., Buliga, E., Letourneau, N. L., Campbell, T. S., \& Giesbrecht, G. F. (2015). Trajectories of sleep quality and associations with mood during the perinatal period. Sleep, 38, 12371245. https://doi.org/10.5665/sleep.4900

Troxel, W. M., Buysse, D. J., Matthews, K. A., Kip, K. E., Strollo, P. J., Hall, M., et al. (2010). Sleep symptoms predict the development of the metabolic syndrome. Sleep, 33, 1633-1640. https://doi. org/10.1093/sleep/33.12.1633

Troxel, W. M., Robles, T. F., Hall, M., \& Buysse, D. J. (2007). Marital quality and the marital bed: Examining the covariation between relationship quality and sleep. Sleep Medicine Reviews, 11, 389404. https://doi.org/10.1016/j.smrv.2007.05.002

Van Straten, A., Van Der Zweerde, T., Kleiboer, A., Cuijpers, P., Morin, C. M., \& Lancee, J. (2017). Cognitive and behavioral therapies in the treatment of insomnia: A meta-analysis. Sleep Medicine Reviews, 38, 3-116. https://doi.org/10.1016/j.smrv.2017.02.001

Wang, G., Deng, Y., Jiang, Y., Lin, Q., Dong, S., Song, Y., et al. (2018). Trajectories of sleep quality from late pregnancy to 36 months postpartum and association with maternal mood disturbances. A longitudinal and prospective cohort study. Sleep, 41, 12. https:// doi.org/10.1093/sleep/zsy179

Weaver, A., Himle, J. A., Taylor, R. J., Matusko, N. N., \& Abelson, J. M. (2015). Urban vs rural residence and the prevalence of depression and mood disorder among African American women and non-Hispanic white women. JAMA Psychiatry, 72, 576-583. https://doi.org/10.1001/jamapsychiatry.2015.10

Wilkerson, A. K., \& Uhde, T. W. (2018). Perinatal sleep problems. Obstetrics and Gynecology Clinics of North America, 45, 483494. https://doi.org/10.1016/j.ogc.2018.04.003

Young, D. R., Sidell, M. A., Grandner, M. A., Koebnick, C., \& Troxel, W. (2020). Dietary behaviors and poor sleep quality among young adult women: Watch that sugary caffeine! Sleep Health, 6, 214-219. https://doi.org/10.1016/j.sleh.2019.12.006

Zambrano, D. N., Mindell, J. A., Reyes, N. R., Hart, C. N., \& Herring, S. J. (2016). "It's not all about my baby's sleep": A qualitative study of factors influencing low-income African American mothers' sleep quality. Behavior Research Methods, 14, 489-500. https://doi.org/10.1080/15402002.2015.1028063 
Publisher's Note Springer Nature remains neutral with regard to jurisdictional claims in published maps and institutional affiliations. 